NASA/TM-2013-217849

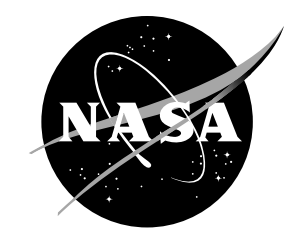

Model Verification and Validation Concepts for a Probabilistic Fracture Assessment Model to Predict Cracking of Knife Edge Seals in the Space Shuttle Main Engine High Pressure Oxidizer

Shantaram S. Pai

Glenn Research Center, Cleveland, Ohio

David S. Riha

Southwest Research Institute, San Antonio, Texas 


\section{NASA STI Program . . . in Profile}

Since its founding, NASA has been dedicated to the advancement of aeronautics and space science. The NASA Scientific and Technical Information (STI) program plays a key part in helping NASA maintain this important role.

The NASA STI Program operates under the auspices of the Agency Chief Information Officer. It collects, organizes, provides for archiving, and disseminates NASA's STI. The NASA STI program provides access to the NASA Aeronautics and Space Database and its public interface, the NASA Technical Reports Server, thus providing one of the largest collections of aeronautical and space science STI in the world. Results are published in both non-NASA channels and by NASA in the NASA STI Report Series, which includes the following report types:

- TECHNICAL PUBLICATION. Reports of completed research or a major significant phase of research that present the results of NASA programs and include extensive data or theoretical analysis. Includes compilations of significant scientific and technical data and information deemed to be of continuing reference value. NASA counterpart of peer-reviewed formal professional papers but has less stringent limitations on manuscript length and extent of graphic presentations.

- TECHNICAL MEMORANDUM. Scientific and technical findings that are preliminary or of specialized interest, e.g., quick release reports, working papers, and bibliographies that contain minimal annotation. Does not contain extensive analysis.

- CONTRACTOR REPORT. Scientific and technical findings by NASA-sponsored contractors and grantees.
- CONFERENCE PUBLICATION. Collected papers from scientific and technical conferences, symposia, seminars, or other meetings sponsored or cosponsored by NASA.

- SPECIAL PUBLICATION. Scientific, technical, or historical information from NASA programs, projects, and missions, often concerned with subjects having substantial public interest.

- TECHNICAL TRANSLATION. Englishlanguage translations of foreign scientific and technical material pertinent to NASA's mission.

Specialized services also include creating custom thesauri, building customized databases, organizing and publishing research results.

For more information about the NASA STI program, see the following:

- Access the NASA STI program home page at http://www.sti.nasa.gov

- E-mail your question to help@sti.nasa.gov

- Fax your question to the NASA STI Information Desk at 443-757-5803

- Phone the NASA STI Information Desk at 443-757-5802

- Write to: STI Information Desk NASA Center for AeroSpace Information 7115 Standard Drive Hanover, MD 21076-1320 
NASA/TM-2013-217849

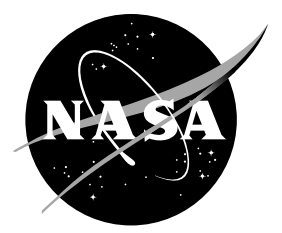

Model Verification and Validation Concepts for a Probabilistic Fracture Assessment Model to Predict Cracking of Knife Edge Seals in the Space Shuttle Main Engine High Pressure Oxidizer

Shantaram S. Pai

Glenn Research Center, Cleveland, Ohio

David S. Riha

Southwest Research Institute, San Antonio, Texas

Prepared for the

Turbo Expo 2012

sponsored by the American Society of Mechanical Engineers (ASME)

Copenhagen, Denmark, June 11-15, 2012

National Aeronautics and

Space Administration

Glenn Research Center

Cleveland, Ohio 44135 


\section{Acknowledgments}

Many people contributed to the development of the probabilistic fracture assessment model to analyze cracking in the space shuttle main engine (SSME) high-pressure oxidizer turbopump (HPOTP) knife edge seals. The success of this effort relied on the experience, expertise, and weekly peer reviews of the models and data. We acknowledge the following for contributing to the success of this effort: Pratt \& Whitney Rocketdyne: Ken Head, Kon Haake, Stuart Montgomery, and George Prueger; NASA Marshall Space Flight Center: Gregory Swanson, Phillip Allen, and Erika Mendoza; and Southwest Research Institute: R. Craig McClung, Michael P. Enright, Carl F. Popelar, Chris J. Waldhart, and Brian M. Gardner.

Trade names and trademarks are used in this report for identification only. Their usage does not constitute an official endorsement, either expressed or implied, by the National Aeronautics and Space Administration.

Level of Review: This material has been technically reviewed by technical management.

Available from

NASA Center for Aerospace Information 7115 Standard Drive

Hanover, MD 21076-1320
National Technical Information Service 5301 Shawnee Road Alexandria, VA 22312 


\title{
Model Verification and Validation Concepts for a Probabilistic Fracture Assessment Model to Predict Cracking of Knife Edge Seals in the Space Shuttle Main Engine High Pressure Oxidizer
}

\author{
Shantaram S. Pai \\ National Aeronautics and Space Administration \\ Glenn Research Center \\ Cleveland, Ohio 44135 \\ David S. Riha \\ Southwest Research Institute \\ San Antonio, Texas 78228
}

\begin{abstract}
Physics-based models are routinely used to predict the performance of engineered systems to make decisions such as when to retire system components, how to extend the life of an aging system, or if a new design will be safe or available. Model verification and validation $(\mathrm{V} \& \mathrm{~V})$ is a process to establish credibility in model predictions. Ideally, carefully controlled validation experiments will be designed and performed to validate models or submodels. In reality, time and cost constraints limit experiments and even model development. This paper describes elements of model V\&V during the development and application of a probabilistic fracture assessment model to predict cracking in space shuttle main engine high-pressure oxidizer turbopump knife-edge seals.

The objective of this effort was to assess the probability of initiating and growing a crack to a specified failure length in specific flight units for different usage and inspection scenarios. The probabilistic fracture assessment model developed in this investigation combined a series of submodels describing the usage, temperature history, flutter tendencies, tooth stresses and numbers of cycles, fatigue cracking, nondestructive inspection, and finally the probability of failure. The analysis accounted for unit-to-unit variations in temperature, flutter limit state, flutter stress magnitude, and fatigue life properties. The investigation focused on the calculation of relative risk rather than absolute risk between the usage scenarios. Verification predictions were first performed for three units with known usage and cracking histories to establish credibility in the model predictions. Then, numerous predictions were performed for an assortment of operating units that had flown recently or that were projected for future flights. Calculations were performed using two NASA-developed software tools: NESSUS ${ }^{\circledR}$ for the probabilistic analysis, and NASGRO ${ }^{\circledR}$ for the fracture mechanics analysis. The goal of these predictions was to provide additional information to guide decisions on the potential of reusing existing and installed units prior to the new design certification.
\end{abstract}

\section{Introduction}

Numerical models are routinely used to predict the performance of engineered systems. Government and industry now routinely rely on model predictions to make such decisions as when to retire system components, how to extend the life of an aging system, or if a new design will be safe or available. The validity of many models used to predict the performance of existing engineered systems have been assessed through historical data but this type of validation is not possible for new designs or designs used in different environments. The validation of new models using experiments becomes more difficult and costly as the complexity and reliability requirements increase. For example, a highly reliable aircraft engine component is difficult to test to failure under operating conditions due to the high reliability. In addition, it may be cost prohibitive to actually test an expensive component to failure. Other systems are impractical to test such as the in vivo measurement of performance measures in human subjects or systems in extreme environments. Valid model predictions become increasingly important as the cost, reliability, and experimental complexity for the engineered system increases.

Model verification and validation (V\&V) provides a systematic approach to establishing confidence in model predictions. Most models requiring this level of validation are complex one-of-a-kind problems and have different time and budget constraints. Experience has shown that a standard and consistent model V\&V methodology may not be practical for these types of problems. This observation is supported by the fact that there are no general standards for model $V \& V$ at this time. However, there are several V\&V guidelines produced by technical committees for computational fluids dynamics (Ref. 1) and solids mechanics (Ref. 2).

The goal of model V\&V is to establish credibility in the model predictions that guide engineering decisions. In many cases the credibility is established in the engineering process. For example, models are developed by experienced analyst and compared to historical data or a single experiment. Conservative values of loads and material strengths may be used to mitigate uncertainties about these parts of the models. 
This process may also include design and/or peer reviews to further establish credibility in the model predictions. From a high level view, a formal model $\mathrm{V} \& \mathrm{~V}$ effort would include validation experiments and metrics that quantify the agreement between model predictions and experiments. In practical applications, the validation experiments may be cost or time prohibitive and analysis must rely on historical performance information or qualification experiments for the comparison. In addition, there may be few experiments or limited historical data for a rigorous statistical quantitative comparison between the model predictions and experiments. Finally, model approximations may be required along with engineering estimates of model parameters due to the time and cost constraints. These approximations, assumptions, and limited data lead to uncertainty in both the model predictions and experiments. Thus uncertainty quantification is an integral part of the model $V \& V$ process.

The goal of this paper is to describe the development of a model that could credibly predict the performance of a complex engineered system for different operating conditions within a tight time and cost budget. The model was developed by experienced analysts, compared to historical data, and peer reviewed frequently. While a formal $V \& V$ process was desired, and engineering approach was required to establish credibility in the model predictions. This paper captures some of the experience gained that can benefit future model V\&V efforts.

\section{Verification and Validation}

Model verification and validation $(\mathrm{V} \& \mathrm{~V})$ is an enabling methodology for the development of computational models that can be used to make predictions with quantified confidence. Model V\&V procedures are needed to reduce the time, cost, and risk associated with component and full-scale testing of products, materials, and engineered systems. Quantifying the confidence and predictive accuracy of model calculations provides the decision-maker with the information necessary for making a risk-informed decision.

Model V\&V is the primary process for quantifying and building credibility in computational models. Verification is the process of determining that a model implementation accurately represents the developer's conceptual description of the model and its solution. Validation is the process of determining the degree to which a model is an accurate representation of the real world from the perspective of the intended uses of the model (Ref. 2). In short, verification is a mathematics issue, whereas validation is a physics issue.

Uncertainty quantification plays a key role in model V\&V. There is uncertainty in the model predictions due to inherent and subjective uncertainties in the model. Likewise, the measurements that are made to validate these simulation outputs also contain errors and uncertainties. While the experimental outcome is used as the reference for comparison, the $\mathrm{V} \& \mathrm{~V}$ process does not presume the experiment to be more accurate than the simulation. Instead, the goal is to quantify the uncertainties in both experimental and simulation results such that the model fidelity requirements can be assessed (validation) and the predictive accuracy of the model quantified.

\section{Uncertainty Quantification}

Uncertainty quantification in the context of model $\mathrm{V} \& \mathrm{~V}$ is use to explicitly account for errors and variations in the model and model input parameters and quantify their impact on the model predictions. These errors and variations are classified more generally as uncertainties; where uncertainties are classified as either irreducible (aleatory) or reducible (epistemic or model error). Examples of aleatory or natural variations include variations in geometry from manufacturing, material properties, and environmental loads. These types of uncertainties can generally be described by a probability density function. Epistemic uncertainties are general model errors such as limited data to fit a PDF (e.g., few experiments to characterize the mean and standard deviation of yield strength) and model form (choice of constitutive material formulation, boundary conditions, and finite element mesh discretization). The uncertainty propagation concept is shown in Figure 1. The model parameters are modeled as PDFs on the left, an appropriate probabilistic algorithm is used to propagate these PDFs through the model (center), resulting in variations in the performance of the system shown by the reliability function on the right. Many uncertainty propagation methods also quantify the importance of the uncertain parameters to the overall model prediction uncertainty. These contributions are represented by the bar chart on the right. The dashed lines on the PDFs on the left represent epistemic uncertainty such as limited data used to estimate parameters for the PDF. These epistemic uncertainties can also be propagated to quantify their impact on the reliability function using appropriate methods.

There are many mature methods to propagating uncertainties when they can be modeled by PDFs. These methods are usually classified as probabilistic methods and include sampling methods, most probable point (MPP) methods, and hybrid methods (combined sampling and MPP) among others. Problems with ill-behaved limit-states or with multiple limitstates, however, generally require the use of sampling based methods or a hybrid approach (Refs. 3 and 4).

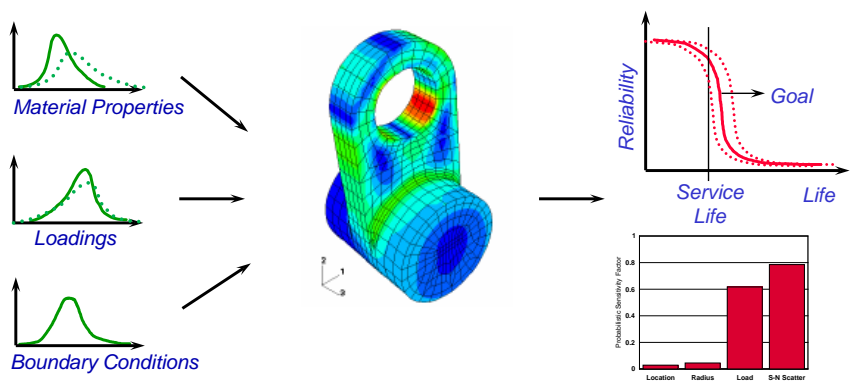

Figure 1.-Uncertainty propagation. 
Sampling methods such as Monte Carlo or Latin Hypercube Simulation (LHS) repeatedly evaluate the deterministic model to generate samples of the model response, from which the response statistics and probability of failure are approximated. A major advantage of sampling methods is that the deterministic model does not need to be simplified or approximated to perform the probabilistic analysis. Thus, problems with multiple failure modes and/or ill-behaved response functions can be solved without difficulty. Another advantage is that the error in the solution can be measured. A significant disadvantage of sampling is that the probabilistic analysis can become quite costly due to the large number of samples required to compute small failure probabilities. One approach to improve the efficiency of sampling based methods is to focus the samples in the important (failure) regions. This class of sampling methods is called importance sampling and can be orders of magnitude more efficient than Monte Carlo simulation (Ref. 5).

\section{Case Study}

Cracking of space shuttle main engine (SSME) highpressure oxidizer turbopump (HPOTP) knife-edge seals (KES) has been observed in several units. Although this cracking did not resulted in the complete fracture of any units, the consequences of such a fracture could be severe. As a result, life limits had been imposed that effectively required the complete replacement of the units following each flight, with substantial cost and schedule implications.

Extensive prior investigations by Pratt \& Whitney Rocketdyne (PWR) and NASA Marshall Space Flight Center (MSFC) determined that these seals are sensitive to fluidstructure instability, or flutter. The relationships between various build parameters (clearances and gaps) and operational environments (local temperatures and pressures) and flutter tendencies were established using flutter experiments on actual seals. The most severely cracked unit was noted to have experienced a flutter event of approximately 15-sec duration during an early green run (ground test run), although the relative significance of this green run versus subsequent flight exposure for the observed cracking was not clear. Subsequent rig testing confirmed the flutter hypothesis. Structural analysis identified the flutter modes most likely to cause cracking and confirmed that local flutter stress levels could be severe enough to cause crack formation and growth.

To reduce risk of HPOTP recycles impacting the STS manifest, effort was undertaken by PWR to develop an on pump inspection capability to reduce the recycle schedule within the existing Deviation Approval Request (DAR) of completing an inspection at 50 percent of the life limit and then flying to the life limit. However, the impact of this approach on the probability of KES cracking was not known. Also unknown were the risk implications of flying the seal to the life limit with no inspection as an alternate method to reduce schedule risk without significantly increasing technical risk.

This effort was performed in parallel to a complete redesign of the turbopump knife-edge seal configuration. The goal of these predictions was to provide additional information to guide decisions on the potential of reusing existing and installed units prior to the new design certification.

\section{Problem Statement and Strategy}

This investigation focused on cracking in the Turbine Outlet Duct (Outboard) 4 Tooth Seal. Analysis was conducted for Tooth A, which exhibited the highest dynamic stresses under the relevant flutter modes. "Failure" due to cracking in the seal was defined as the development of a 0.075 in. radial through crack in the seal tooth, which corresponds to crack growth through the entire tooth, up to the edge of the web. This is a conservative definition of failure, since cracks have been observed to grow into the web without causing complete fracture of the seal. The objective of the effort was to assess the probability of initiating and growing a crack to this length in specific flight units. The analysis accounted for unit-to-unit variations in temperature, flutter stress magnitude, and fatigue life properties.

The assessment was performed for four different usage and inspection scenarios, employing consistent assumptions about common variables:

1. Current flight requirements: A new seal experiencing 1 green run and 1 flight.

2. A new seal experiencing 1 green run and 1 flight, followed by an eddy-current inspection, and then an additional green run and flight.

3. A new seal experiencing 1 green run and 3 subsequent flights with no inspection or replacement.

4. A new seal experiencing 1 green run, 1 nominal flight, and 1 flight containing an abort.

This investigation focused on the calculation of relative risk rather than absolute risk. In other words, how much does the risk change for the different usage/inspection scenarios? These calculated risk numbers were also put into perspective by comparing them with calculated risk numbers for specific units with known cracking histories. The number of cracks and crack sizes for the units with known cracking histories were used as a form of validation data. The models were used to predict the variation in crack size for the units with known histories and compared to the cracking history to establish credibility in the model predictions.

The physics of the fluid-structure interactions are complex in this severe and uncertain loading environment, and thus empirical models based on experimental data were used for portions of the model to predict flutter and flutter stresses. Once load conditions were estimated using this combination of empirical and numerical models, established fatigue crack growth models were applied to predict the extent of crack 
propagation during green runs or flights. Model predictions were compared to selected cracking data to validate the model.

Calculations were performed using two NASA-developed software tools: NESSUS (Ref. 6) for the probabilistic analysis, and NASGRO (Ref. 7) for the fracture mechanics analysis. NESSUS is a general-purpose probabilistic analysis program with a suite of traditional and advanced probabilistic methods. NASGRO, which is the standard fracture control software for all NASA Centers, computes fatigue crack growth (FCG) and fracture for different materials, loads, and structural geometries.

\section{Probabilistic Fracture Assessment Model}

The probabilistic fracture assessment model developed and used in this investigation combined a series of submodels describing the usage, temperature history, flutter tendencies, tooth stresses and numbers of cycles, fatigue cracking, nondestructive inspection, and finally the probability of failure (Fig. 2). Usage information characterized the different sequences of green runs and flights considered for each unit. The temperature model predicted the turbine exit temperature history and associated uncertainty for each unit as a function of time. The flutter model used operating conditions and build clearances to determine key parameters (ACD Ratio and $\Delta \mathrm{P}$ ) that are predictors of flutter tendencies and then compared these parameters with the flutter limit state to determine the flutter condition at each time increment in the history. The stress model interpreted the flutter model to predict dynamic stress amplitudes in the seal tooth at these time increments and assign numbers of cycles based on flutter frequencies. The fatigue model used high cycle fatigue and fatigue crack growth properties to perform an integrated fatigue crack initiation and growth simulation for the seal tooth subjected to these stress amplitudes with known stress gradients and superimposed static stresses. Where appropriate, the inspection model simulated a probabilistic eddy current inspection and determined if a crack was detected. The probability of failure (crack size $>0.075$ in.) occurring in each unit for each usage scenario was calculated and compared with benchmark failure probabilities calculated for verification units with known usage and cracking histories. The analysis accounted for unit-to-unit variations and uncertainties in temperature, flutter limit state, flutter stress magnitude, and fatigue life properties.

The probabilistic fracture model components were integrated using two NASA-developed software tools: NESSUS for the probabilistic analysis and NASGRO for the fracture mechanics analysis. The random variables included the temperature distribution variations, flutter limit state uncertainty, the maximum flutter stress, the flutter frequency, the uncertainty on the fatigue crack growth model, and probability of detection for the inspection. The number of random variables needed to define the temperature model is case specific and also depends on the use of measured or model based temperature histories. The different cases have different numbers of green runs and starts.

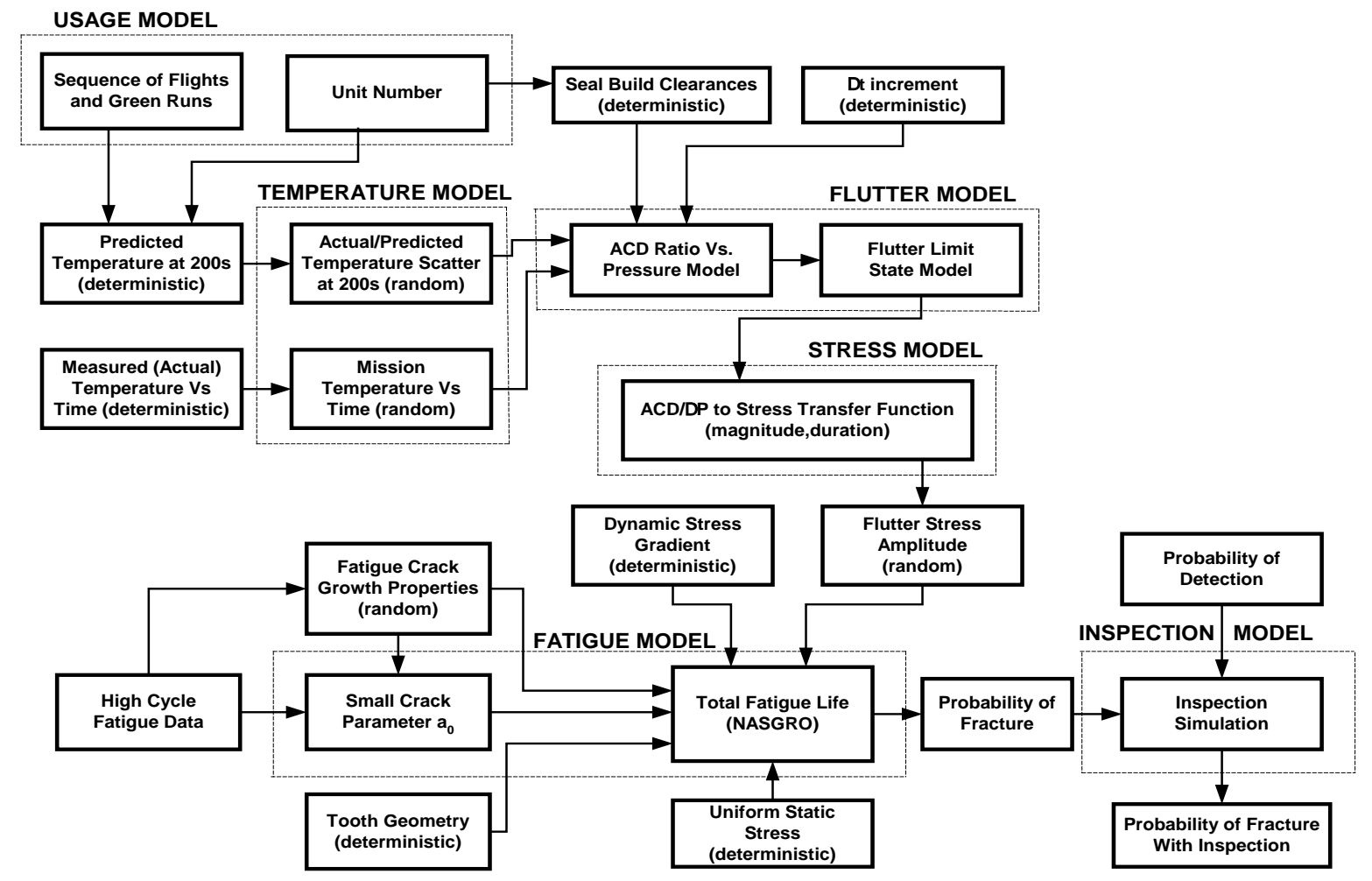

Figure 2.-Probabilistic fracture assessment model flow chart. 
The highly nonlinear crack growth response and noncontinuous response functions required the use of a samplingbased method to compute the probability of failure and the cumulative distribution function. The probabilistic analysis for each unit and usage scenario was performed using the Monte Carlo simulation algorithm in NESSUS.

\section{HPOTP Usage Scenarios}

The green run is a start that operates the turbopump through all potential power settings to verify correct operation of new and rebuilt pumps. Two durations of the green run profile are used depending on the rebuild status of the pump: pumps that are new or have a major rebuild use the long green run, and those with minor rebuilds use a short green run profile. The standard flight profile consists of a short duration 104.5 percent power setting followed by the so-called "bucket" decrease in power (to reduce aerodynamic forces) and then by a long duration 104.5 percent power setting until orbit is reached.

\section{Temperature Models}

The turbine exit temperature was found to be one of the most important variables affecting KES flutter and fatigue cracking. This temperature is one of the key inputs to the calculation of the ACD ratio and $\Delta \mathrm{P}$ values (see the following section on Flutter Models), which directly impact dynamic stresses. Measured turbine exit temperature profiles were available for previously flown units. Measured temperatures were obviously unavailable for unflown units, so a model was developed to estimate the temperatures associated with these units. Both the measured and model-based temperatures considered uncertainties. These temperature models were then combined to generate full temperature histories for each usage scenario based on defined power profiles for green runs, normal flights, and aborts.

\section{Flutter Models}

Evaluation of the flutter rig experimental data by PWR indicated that tendencies for flutter were predicted by particular combinations of values of the ACD ratio and a specific pressure drop $\Delta \mathrm{P}$. The ACD ratio is a function of the geometry of the seals. The model for flutter developed in this study, therefore, consisted of two parts. The first part of the model involved predicting values of the ACD ratio and $\Delta \mathrm{P}$ for specific units as a function of build clearances and operating conditions (power setting and temperature). The second part of the model involved defining a "flutter limit state" (FLS) that related these ACD and $\triangle \mathrm{P}$ values to flutter occurrence.

Two of the key inputs into the flutter limit state model are the definition of the ACD ratio and pressure differential for the current unit. The ACD ratio is defined by the effective areas of the seal geometry. These values are functions of the as-built clearances and associated operating conditions. The pressure differential $(\Delta \mathrm{P})$ is measured across the four-tooth seal. The ACD and $\triangle \mathrm{P}$ values were computed using a proprietary flow network solver for each unit configuration, temperature, and power setting. A simple regression model was developed to describe the changes in ACD and $\triangle \mathrm{P}$ due to changes in power level and turbine exit temperature for a single unit. This regression model could then be used to predict ACD and $\Delta \mathrm{P}$ values for any unit and any combination of power level and turbine exit temperature, given that a single anchor point (ACD vs. $\triangle \mathrm{P}$ for a specific power level and temperature) for this unit was provided by a flow network solver.

PWR had developed a flutter test rig to investigate whether flow-induced flutter was a credible failure scenario and to characterize the flutter sensitivity and dynamic response of the KES through parametric variations of flow and clearance conditions. These experiments did not include service temperatures, two-phase flow, or rotation of an actual unit. However, the experiments were expected to predict similar flutter strain response to the operating units for comparable controlled values of $\mathrm{ACD}$ and $\triangle \mathrm{P}$, and therefore the flutter rig tests were used as the basis for the developed flutter models. When flutter occurred, dynamic strains in the seal teeth increased dramatically, and therefore large measured dynamic strains served as an indication of flutter.

As noted earlier, the ACD ratio and $\triangle \mathrm{P}$ values were found to correlate with tendencies for flutter; in particular, flutter was found to occur at higher values of ACD and $\triangle \mathrm{P}$. Three flutter rig experiments were performed and points in ACD- $\Delta \mathrm{P}$ space were identified corresponding to flutter conditions and noflutter conditions. This line is called the "flutter limit state" (FLS).

The validity of this line was verified by comparing predicted strains to the experiments. Approximate upper and lower bounds on this FLS were set visually to account for some of the misclassification of flutter and no-flutter points. These approximate upper and lower bounds were assumed to correspond to plus or minus three standard deviations from the central tendency (mean value) FLS. Uncertainty in the FLS was modeled (using these approximate standard deviations) as a parallel shift that changed the intercept of the FLS line but not its slope. Attempts to refine the FLS uncertainty model using more rigorous statistical regressions were not supported by the available data. The uncertainty model was judged to be sufficiently accurate for the relative probability comparisons between different units.

\section{Stress Model}

Flutter conditions have to be quantified into specific KES tooth stress levels in order to perform fatigue assessments. An approximate stress model was developed to serve this purpose. In this approximate model, the amplitude of the dynamic stresses was assumed to be directly proportional to the perpendicular distance (d) from the FLS in ACD- $\triangle \mathrm{P}$ space. At the FLS, the dynamic stress amplitude was assumed to be zero. 
The engine upper operating threshold was used to define the maximum possible perpendicular distance (D) away from the FLS. The intercept of the engine upper operating threshold was defined for a specific unit at 104.5 percent green run power setting in ACD- $\Delta \mathrm{P}$ space.

A wide range of flutter modes is possible in the knife-edge seal. The $8^{\text {th }}$ nodal diameter mode (and its close neighbors) is believed to be the most severe stress condition and also the primary source of cracking of a known cracked unit. Therefore, the stress model used in this study was focused on the $8^{\text {th }}$ nodal diameter mode.

The maximum possible dynamic stress amplitude value was taken to be the predicted stress in the $8^{\text {th }}$ nodal diameter mode for the seal at the maximum possible deflection value, which is defined by the clearance. This dynamic stress value was determined for the known cracked unit and assigned a normal distribution with a coefficient of variation of 10 percent. The actual standard deviations were not known for this variable, but these values were used consistently for all analyses in order to support relative probability comparisons between units. A uniform static stress was also superimposed, representing nominal conditions without flutter.

\section{Fatigue Model}

The HPOTP knife edge seals are fabricated from Incoloy 909 and experience in-service metal temperatures of about 250 to $350{ }^{\circ} \mathrm{F}$ in a two-phase, fuel-rich steam environment comprising a mixture of GH2, steam, and liquid water. Fatigue crack growth (FCG) rate data for this material in a GH2 plus steam environment at $300^{\circ} \mathrm{F}$ had been previously generated from compact tension (through crack) and surface crack specimens under both constant amplitude and $K$ gradient load histories at a variety of stress ratios. These data, corrected for crack closure (Ref. 8), were used to develop the NASGRO fatigue crack growth relation. No threshold was included in this model.

A small-crack model, originally proposed by El Haddad (Ref. 9), was used to model fatigue crack growth initiation. This small-crack model results in a non-zero growth rate for vanishingly small physical crack sizes. As the crack size increases, the small-crack effects become increasing negligible. In this way, the small-crack model facilitates a single FCG analysis that incorporates both initiation and propagation phases of life over the entire range of crack sizes. This approach is preferable to a more traditional calculation of crack "initiation" life based on the failure of a smooth test specimen, because the entire KES tooth is actually smaller than the customary smooth fatigue specimen. The small-crack model was developed from available smooth HCF data at $300{ }^{\circ} \mathrm{F}$ in a GH2 + steam environment in both the nominal material condition and a pre-exposed (supercharged) material condition.

Fatigue cracking was modeled as a corner crack in a rectangular plate that transitions into a through edge crack in a plate of variable thickness. NASGRO analyses were performed with a special pre-production version of the software in order to take advantage of two new weight function (WF) stress intensity factor (SIF) solutions that had not yet been implemented in the current (at the time of the investigation) production version, NASGRO 5.0. The first new SIF solution was a univariant WF solution for the corner crack in a plate based on the classical Shen and Glinka approach (Ref. 10). The second SIF solution was a univariant WF solution for the through edge crack in a plate of variable thickness with arbitrary stress gradients along the length of the plate. Both solutions were modified to include small-crack effects. The NASGRO source code was further modified to facilitate a direct transition from the corner crack to the through edge crack at a crack of 95 percent of the plate width.

\section{Inspection Model}

A special eddy current inspection (ECI) method was developed for an on pump inspection capability to reduce the recycle schedule within the existing Deviation Approval Request (DAR) of completing an inspection at 50 percent of the life limit and then flying to the life limit. This investigation was performed to assess the risk implications of that approach. This inspection was included in one usage scenario (denoted as Case 2), which contained a green run and flight, followed by the ECI inspection, and then (if no crack was detected) another green run and flight. The inspection model compared the predicted crack length following a green run and flight with a detectable flaw size. If the predicted crack length after the first green run and flight was less than the detectable flaw size, the predicted flaw was not detected. The seal would then be subjected to a second green run and flight, from which a final crack length would be predicted.

Not all flaws that exceed a nominal detectable length will actually be detected. The detectable flaw size is not a deterministic value, but has some uncertainty due to the efficacy of the inspection method. This uncertainly is characterized as the probability of detection (POD). The POD is the (cumulative) probability of detecting flaws greater than a given crack length.

\section{Probabilistic Fracture Assessment Predictions}

The probabilistic fracture assessment predictions were performed using (1) "verification" units to demonstrate the predictive capability of the developed models and (2) "operating" units to predict the probabilities associated with current and future flight units. The verification units were chosen for their different temperature history severities and known cracking conditions. The operating units were recently flown or were scheduled for a future flight. The probabilistic predictions were performed using the specific temperature and build conditions for each unit. 


\section{Verification Units}

Verification predictions were first performed for three units with known usage and cracking histories. Unit A had experienced a severe thermal history and had exhibited severe cracking. Unit B had experienced many starts, slightly elevated temperatures, and substantial cracking (this unit had one through tooth crack of 0.075 in. and numerous smaller cracks). Unit $\mathrm{C}$ had limited exposure, a benign build, and no observed cracking. The fracture assessment model successfully predicted the contrasting failure probabilities that were consistent with the observed cracking behavior for all three units. Unit B is used as the baseline unit for relative reliability comparisons of operating units. More informed decisions for using a unit for an additional flight without inspection can be made by assessing the relative reliability with respect to unit B.

The cumulative distribution function (CDF) of the final crack size is shown in Figure 3 for each of the three verification units. The left y-axis displays the cumulative probability in standard normal units. The crack size is plotted in $\log$ scale along the bottom axis. This CDF indicates reliability - the cumulative probability that the crack size is less than a specific crack size. The probability of failure is one minus the reliability. A comparison of the CDFs in Figure 3 for each verification unit demonstrates the validity of the developed models. Unit $C$ was expected to have the least crack growth due to its location in ACD- $\Delta \mathrm{P}$ space and benign temperatures. Unit A was expected to have the largest cracks. Unit B was expected be somewhere in between. The results shown in Figure 3 support the relative predictive capability of the models. The probabilistic results for the operating units summarized in the next section are compared to the model predictions for unit $\mathrm{B}$ in order to make a relative comparison to two known cracked cases.

\section{Operating Units}

Using the verified models, predictions were performed for an assortment of operating units that had flown recently or that were projected for future flights. These computations assessed the final crack size distribution and probability of failure for the various usage scenarios. All results were normalized against similar predictions for the baseline verification unit B.

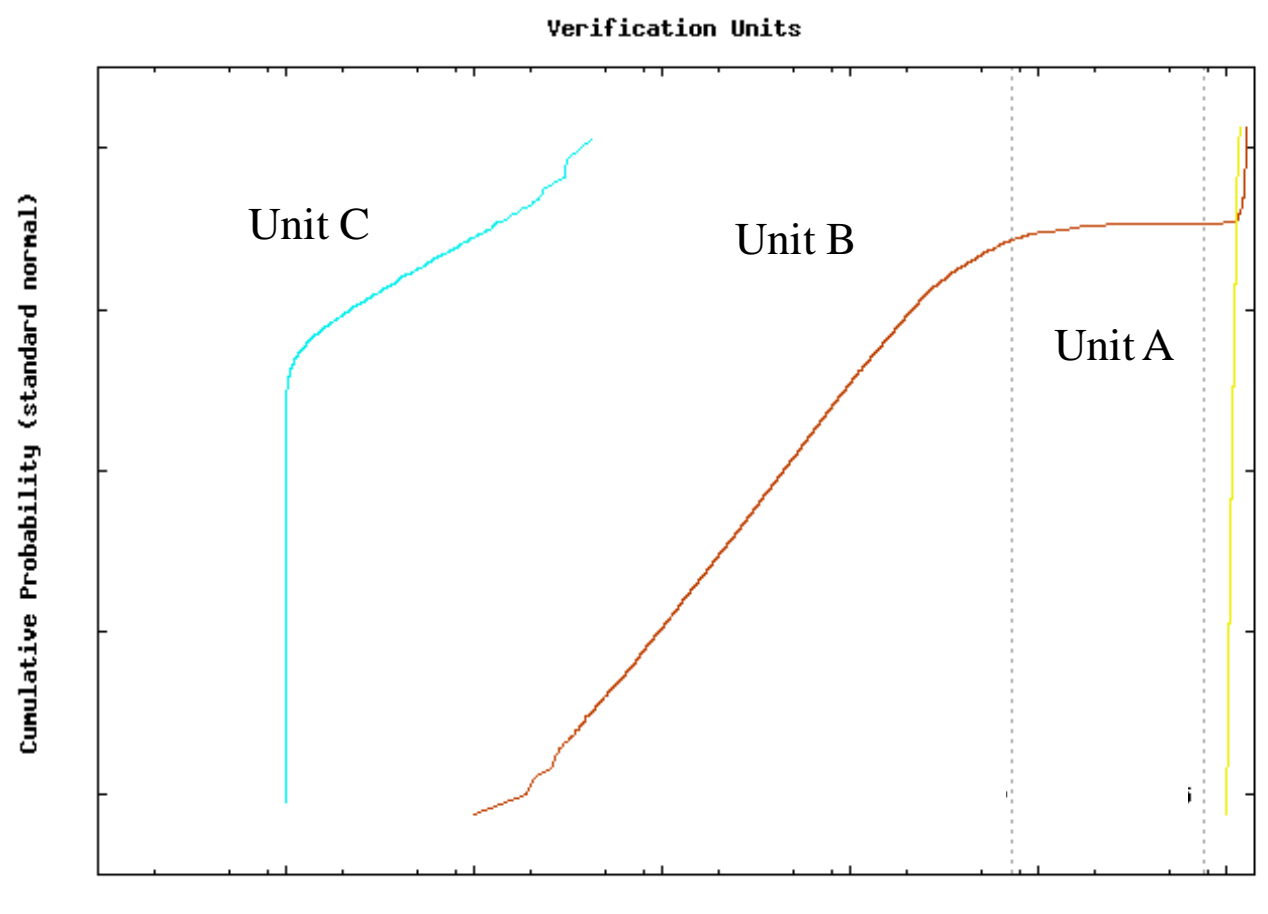

Final Crack Size

Figure 3.-CDF of final crack size for the verification units. 


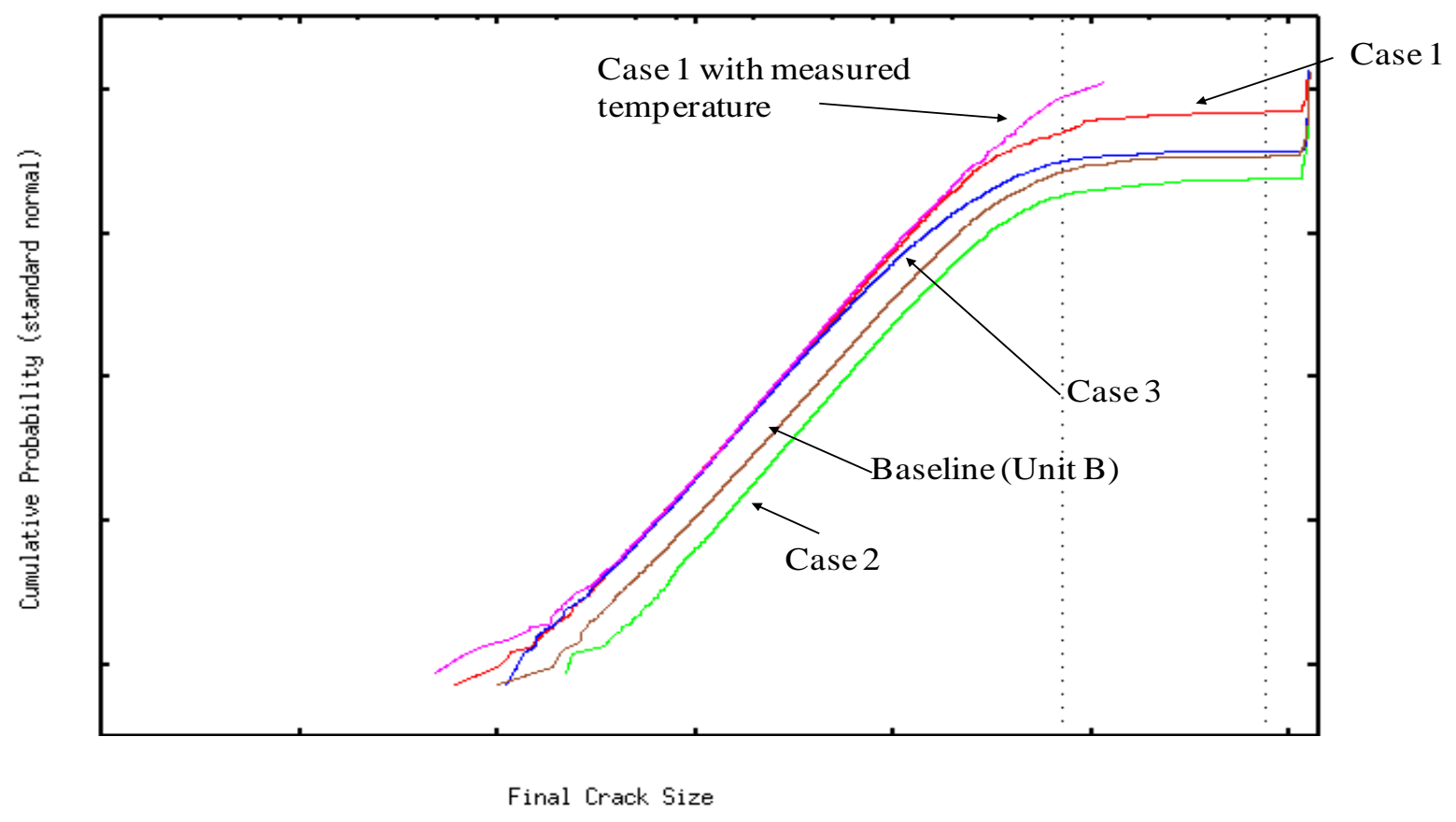

Figure 4.-CDF of final crack size for an operating unit.

The deterministic and probabilistic variables needed for the probabilistic fracture assessment model were described for each part of the model. Each unit analyzed was defined by the build parameters and temperature history profiles. The temperature random variable definitions were different for each unit and case (usage scenario). Parameters for the flutter, stress, FCG, and inspection models were the same for each analyzed unit and usage scenario. The cases are described below:

- Case 1 requires one green run and one flight.

- Case 2 adds the inspection and another green run and flight. Additional random variables were required for the temperature model to account for the green run and flight after inspection. The inspection model also requires the distribution for detectable crack sizes.

- Case 3 requires one green run and three flights with additional temperature variables to account for the temperature variability between each flight.

An operating unit has a known green run temperature history, and the initial analysis used the model-based flight temperature history for the three operating scenarios. This unit was flown during this study so a measured flight temperature history also became available. The Case 1 usage scenario was also analyzed using the measured flight temperature history. The CDFs for this unit for the different scenarios are shown in Figure 4 along with the CDF for unit $\mathrm{B}$ for a relative comparison. Case 1 using the model-based temperature history shows a higher reliability compared to unit B. Adding two additional flights (Case 3) introduced a slight reliability penalty but still demonstrated a higher reliability than unit B. The addition of the inspection (Case 2) reduced the reliability below that predicted for unit $\mathrm{B}$. The additional green run required after the inspection increased the exposure at the high power setting so the unit experienced additional time in the flutter region. In this case, the additional green run required following inspection is more damaging than two additional flights. Finally, the unit was also analyzed using the actual flown temperature histories. The CDF using the measured temperature values demonstrated a higher reliability than that using the model-based temperature history. The measured flight temperature history removed some of the uncertainty from the temperature model. In this case, the model-based temperature history was conservative (a lower reliability was computed).

\section{Case Study Summary}

The impact of different usage and inspection scenarios on fatigue cracking due to flutter in SSME HPOTP knife-edge seals was assessed. A probabilistic fracture assessment model was developed that combined a series of submodels describing the usage, temperature history, flutter tendencies, tooth stresses and numbers of cycles, fatigue cracking, nondestructive inspection, and finally the probability of failure. The probability of failure (crack size $>0.075$ in.) occurring in each unit for each usage scenario was calculated and compared with benchmark failure probabilities calculated for verification units with known usage and cracking histories. The analysis accounted for unit-to-unit variations and uncertainties in temperature, flutter limit state, flutter stress magnitude, and fatigue life properties. Calculations were performed using two 
NASA-developed software tools: NESSUS for the probabilistic analysis and NASGRO for the fracture mechanics analysis.

Verification predictions were first performed for three units with known usage and cracking histories. The probabilistic fracture assessment model successfully predicted widely contrasting failure probabilities that were consistent with the observed cracking behavior for all three units. Numerous predictions were performed for an assortment of operating units that had flown recently or that were projected for future flights, and all of these results were tabulated. These computations assessed the final crack size distribution and probability of failure for the various usage scenarios. While absolute reliability values were not predicted, more informed decisions for using a unit for an additional flight without inspection can be made by assessing the relative reliability with respect to the baseline unit.

\section{Conclusions}

This paper describes the development and application of a probabilistic fracture assessment model to analyze cracking in the SSME HPOTP knife edge seals. The probabilistic fracture assessment model consisted of a series of submodels, each of which had their own physics, assumptions, and uncertainties. The development of each submodel included some level of verification and validation leading to improved confidence in the predictive capability of the integrated probabilistic fracture assessment model. Due to time and cost constraints for using these models to make decisions, rigorous model $\mathrm{V} \& \mathrm{~V}$ was not performed for each submodel. However, many concepts for model $\mathrm{V} \& \mathrm{~V}$ were exercised during the engineering model development process such as verification of each submodel, validation against experimental results when available, model comparison to historical data for model validation, and frequent peer reviews.

Model V\&V is a process to establish credibility in model predictions. Ideally, carefully controlled validation experiments will be designed and performed to validate models or submodels. In reality, time and cost constraints limit experiments and even model development. Communication of the assumptions and uncertainties are even more important due to these constraints. Incorporating UQ into the model predictions provides a rigorous approach to communicate the impact of assumptions and uncertainties in the model predictions. A major benefit of this process is communicating the model and data assumptions and uncertainties for peer reviews and to the decision makers. Thus decisions based on model predictions can be made in light of the assumptions and uncertainties.

\section{References}

1. American Institute of Aeronautics and Astronautics, 1998, AIAA Guide for the Verification and Validation of Computational Fluid Dynamics Simulations, AIAA, Reston, VA.

2. American Society of Mechanical Engineers, 2006, Guide for Verification and Validation in Computational Solid Mechanics, ASME, New York, NY.

3. Thacker, B. H., Riha, D. S., Millwater, H. R., Enright, M. P., "Errors and Uncertainties in Probabilistic Engineering Analysis,” 2001, Proc. AIAA/ASME/ASCE/AHS/ASC 42nd Structures, Structural Dynamics, and Materials (SDM) Conference, Seattle, WA, AIAA-2001-1239.

4. Riha, D. S., Thacker, B. H., Fitch, S. H. K., 2004, "NESSUS Capabilities for Ill-Behaved Performance Functions," Proc. AIAA/ASME/ASCE/AHS/ASC 45th Structures, Structural Dynamics, and Materials (SDM) Conf., Palm Springs, CA, AIAA-2004-1832.

5. Wu, Y.T. Computational Method for Efficient Structural Reliability and Reliability Sensitivity Analysis. AIAA J. 1994; 32.

6. Thacker, B. H., Riha, D. S. Fitch, S. K. Huyse, L. J. and Pleming, J. B., "Probabilistic Engineering Analysis Using the NESSUS Software," Structural Safety, Vol. 28, No. 12, 2006, pp. 83-107.

7. Southwest Research Institute (SwRI) and NASA Johnson Space Center. NASGRO ${ }^{\circledR}$ Fracture Mechanics and Fatigue Crack Growth Analysis Software, Version 5.2 Reference Manual, SwRI, 2008.

8. Newman, J. C., Jr., 1984, “A Crack Opening Stress Equation for Fatigue Crack Growth,” International Journal of Fracture, Vol. 24, pp. R131-R135.

9. El Haddad, M. H., Smith, K. N., and Topper, T. H., 1979, "Fatigue Crack Propagation of Short Cracks," Journal of Engineering Materials and Technology, Vol. 101, pp. 42-46.

10. Shen G., and Glinka, G., 1991, "Weight Functions for a Surface Semi-Elliptical Crack in a Finite Thickness Plate," Theoretical and Applied Fracture Mechanics, Vol. 15, 1991, pp. 247-255. 


\begin{tabular}{|c|c|c|c|c|c|}
\hline \multicolumn{5}{|c|}{ REPORT DOCUMENTATION PAGE } & $\begin{array}{l}\text { Form Approved } \\
\text { OMB No. 0704-0188 }\end{array}$ \\
\hline \multicolumn{6}{|c|}{ 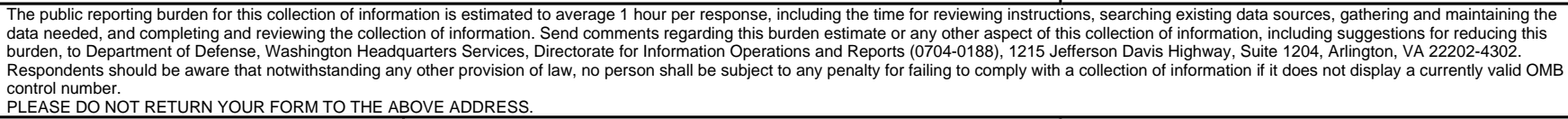 } \\
\hline \multicolumn{2}{|c|}{$\begin{array}{l}\text { 1. REPORT DATE (DD-MM-YYYY) } \\
01-04-2013\end{array}$} & \multicolumn{3}{|c|}{$\begin{array}{l}\text { 2. REPORT TYPE } \\
\text { Technical Memorandum }\end{array}$} & 3. DATES COVERED (From - To) \\
\hline \multirow{3}{*}{\multicolumn{5}{|c|}{$\begin{array}{l}\text { 4. TITLE AND SUBTITLE } \\
\text { Model Verification and Validation Concepts for a Probabilistic Fracture Assessment Model } \\
\text { Predict Cracking of Knife Edge Seals in the Space Shuttle Main Engine High Pressure } \\
\text { Oxidizer }\end{array}$}} & 5a. CONTRACT NUMBER \\
\hline & & & & & 5b. GRANT NUMBER \\
\hline & & & & & 5c. PROGRAM ELEMENT NUMBER \\
\hline \multirow{3}{*}{\multicolumn{5}{|c|}{$\begin{array}{l}\text { 6. AUTHOR(S) } \\
\text { Pai, Shantaram, S.; Riha, David, S. }\end{array}$}} & 5d. PROJECT NUMBER \\
\hline & & & & & 5e. TASK NUMBER \\
\hline & & & & & $\begin{array}{l}\text { 5f. WORK UNIT NUMBER } \\
\text { WBS 724297.20.21.12 }\end{array}$ \\
\hline \multicolumn{5}{|c|}{$\begin{array}{l}\text { 7. PERFORMING ORGANIZATION NAME(S) AND ADDRESS(ES) } \\
\text { National Aeronautics and Space Administration } \\
\text { John H. Glenn Research Center at Lewis Field } \\
\text { Cleveland, Ohio 44135-3191 }\end{array}$} & $\begin{array}{l}\text { 8. PERFORMING ORGANIZATION } \\
\text { REPORT NUMBER } \\
\text { E-18636 }\end{array}$ \\
\hline \multirow{2}{*}{\multicolumn{5}{|c|}{$\begin{array}{l}\text { 9. SPONSORING/MONITORING AGENCY NAME(S) AND ADDRESS(ES) } \\
\text { National Aeronautics and Space Administration } \\
\text { Washington, DC 20546-0001 }\end{array}$}} & $\begin{array}{l}\text { 10. SPONSORING/MONITOR'S } \\
\text { ACRONYM(S) } \\
\text { NASA }\end{array}$ \\
\hline & & & & & $\begin{array}{l}\text { 11. SPONSORING/MONITORING } \\
\text { REPORT NUMBER } \\
\text { NASA/TM-2013-217849 }\end{array}$ \\
\hline \multicolumn{6}{|c|}{$\begin{array}{l}\text { 12. DISTRIBUTION/AVAILABILITY STATEMENT } \\
\text { Unclassified-Unlimited } \\
\text { Subject Category: } 15 \\
\text { Available electronically at http://www.sti.nasa.gov } \\
\text { This publication is available from the NASA Center for AeroSpace Information, 443-757-5802 }\end{array}$} \\
\hline \multicolumn{6}{|c|}{ 13. SUPPLEMENTARY NOTES } \\
\hline \multicolumn{6}{|c|}{$\begin{array}{l}\text { 14. ABSTRACT } \\
\text { Physics-based models are routinely used to predict the performance of engineered systems to make decisions such as when to retire system } \\
\text { components, how to extend the life of an aging system, or if a new design will be safe or available. Model verification and validation (V\&V) } \\
\text { is a process to establish credibility in model predictions. Ideally, carefully controlled validation experiments will be designed and performed } \\
\text { to validate models or submodels. In reality, time and cost constraints limit experiments and even model development. This paper describes } \\
\text { elements of model V\&V during the development and application of a probabilistic fracture assessment model to predict cracking in space } \\
\text { shuttle main engine high-pressure oxidizer turbopump knife-edge seals. The objective of this effort was to assess the probability of initiating } \\
\text { and growing a crack to a specified failure length in specific flight units for different usage and inspection scenarios. The probabilistic } \\
\text { fracture assessment model developed in this investigation combined a series of submodels describing the usage, temperature history, flutter } \\
\text { tendencies, tooth stresses and numbers of cycles, fatigue cracking, nondestructive inspection, and finally the probability of failure. The } \\
\text { analysis accounted for unit-to-unit variations in temperature, flutter limit state, flutter stress magnitude, and fatigue life properties. The } \\
\text { investigation focused on the calculation of relative risk rather than absolute risk between the usage scenarios. Verification predictions were } \\
\text { first performed for three units with known usage and cracking histories to establish credibility in the model predictions. Then, numerous } \\
\text { predictions were performed for an assortment of operating units that had flown recently or that were projected for future flights. } \\
\text { Calculations were performed using two NASA-developed software tools: NESSUS }{ }^{\circledR} \text { for the probabilistic analysis, and NASGRO for the } \\
\text { fracture mechanics analysis. The goal of these predictions was to provide additional information to guide decisions on the potential of } \\
\text { reusing existing and installed units prior to the new design certification. }\end{array}$} \\
\hline \multicolumn{6}{|c|}{$\begin{array}{l}\text { 15. SUBJECT TERMS } \\
\text { Seals; Frequency; Knife edge seals; Cracking }\end{array}$} \\
\hline \multicolumn{3}{|c|}{ 16. SECURITY CLASSIFICATION OF: } & $\begin{array}{l}\text { 17. LIMITATION OF } \\
\text { ABSTRACT }\end{array}$ & $\begin{array}{l}\text { 18. NUMBER } \\
\text { OF }\end{array}$ & $\begin{array}{l}\text { 19a. NAME OF RESPONSIBLE PERSON } \\
\text { STI Help Desk (email:help@sti.nasa.gov) }\end{array}$ \\
\hline $\begin{array}{l}\text { a. REPORT } \\
\text { U }\end{array}$ & $\begin{array}{l}\text { b. ABSTRACT } \\
\text { U }\end{array}$ & $\begin{array}{l}\text { c. THIS } \\
\text { PAGE } \\
\text { U }\end{array}$ & UU & $\begin{array}{c}\text { PAGES } \\
16\end{array}$ & $\begin{array}{l}\text { 19b. TELEPHONE NUMBER (include area code) } \\
443-757-5802\end{array}$ \\
\hline
\end{tabular}



